\title{
Otx2 Binding to Perineuronal Nets Persistently Regulates Plasticity in the Mature Visual Cortex
}

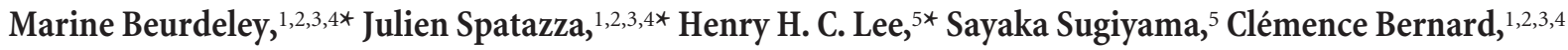 \\ Ariel A. Di Nardo, ${ }^{1,2,3,4}$ Takao K. Hensch, ${ }^{5}$ and Alain Prochiantz ${ }^{1,2,3,4}$ \\ ${ }^{1}$ Collège de France, Center for Interdisciplinary Research in Biology, F-75005 Paris, France, ${ }^{2}$ Centre National de la Recherche Scientifique, UMR 7241, \\ F-75005 Paris, France, ${ }^{3}$ Institut National de la Santé et de la Recherche Médicale, U1050, F-75005 Paris, France, ${ }^{4}$ Labex Memolife, PSL Research University, \\ F-75005 Paris, France, and ${ }^{5}$ F. M. Kirby Neurobiology Center, Children's Hospital Boston, Harvard Medical School, Boston, Massachusetts 02115
}

Specific transfer of (orthodenticle homeobox 2) 0tx2 homeoprotein into GABAergic interneurons expressing parvalbumin (PV) is necessary and sufficient to open, then close, a critical period (CP) of plasticity in the developing mouse visual cortex. The accumulation of endogenous Otx2 in PV cells suggests the presence of specific Otx2 binding sites. Here, we find that perineuronal nets (PNNs) on the surfaces of PV cells permit the specific, constitutive capture of Otx 2 . We identify a 15 aa domain containing an arginine-lysine doublet (RK peptide) within 0tx2, bearing prototypic traits of a glycosaminoglycan (GAG) binding sequence that mediates Otx2 binding to PNNs, and specifically to chondroitin sulfate $\mathrm{D}$ and $\mathrm{E}$, with high affinity. Accordingly, PNN hydrolysis by chondroitinase $\mathrm{ABC}$ reduces the amount of endogenous 0tx2 in PV cells. Direct infusion of RK peptide similarly disrupts endogenous Otx2 localization to PV cells, reduces PV and PNN expression, and reopens plasticity in adult mice. The closure of one eye during this transient window reduces cortical acuity and is specific to the RK motif, as an Alanine-Alanine variant or a scrambled peptide fails to reactivate plasticity. Conversely, this transient reopening of plasticity in the adult restores binocular vision in amblyopic mice. Thus, one function of PNNs is to facilitate the persistent internalization of Otx2 by PV cells to maintain CP closure. The pharmacological use of the 0tx2 GAG binding domain offers a novel, potent therapeutic tool with which to restore cortical plasticity in the mature brain.

\section{Introduction}

During infancy, distinct brain regions exhibit transient critical periods (CPs) of heightened plasticity (Hensch, 2004). In the binocular primary visual cortex (V1b), monocular deprivation (MD) during a CP leads to a rapid shift in neuronal spiking response in favor of the open eye (Wiesel and Hubel, 1963) and an enduring loss of visual acuity to the deprived eye (Morishita and Hensch, 2008). Limited plasticity beyond a CP poses a challenge for recovery from amblyopia, a condition affecting 3-5\% of the human population (Holmes and Clarke, 2006). Enabling

\footnotetext{
Received Jan. 27, 2012; revised March 11, 2012; accepted April 8, 2012.

Author contributions: J.S., T.K.H., and A.P. designed research; M.B., J.S., H.H.C.L., S.S., C.B., and A.A.D.N. performed research; M.B., J.S., and H.H.C.L. analyzed data; T.K.H. and A.P. wrote the paper.

In addition to institutional support, this study was funded by L'Agence nationale pour la recherche Grant ANR08-BLAN-0612 (A.P.), Fondation pour la Recherche médicale (FRM; Team and longévité cognitive et sensorielle) Grant DLC20060206418 (A.P.), Global Research Laboratory Program Grant 2009-00424 from the Korean Ministry of Education, Science and Technology (A.P.), and Région lle de France (A.P.). T.K.H. is supported by National Institutes of Health Grant 1 DP1 OD 003699-01. M.B. is an FRM fellow. J.S. is a Centre national de la recherche scientifiqueBourses de doctorat pour ingénieur recipient. H.H.C.L. is a Croucher Foundation (Hong Kong, Peoples Republic of China) Fellow. We thank M. Volovitch and Dr. A. Joliot for useful discussions. We also thank A. Perrot and Drs. A. Walrant and Professor S. Sagan, who kindly helped with the isothermal titration calorimetry.

${ }^{*}$ M.B., J.S., and H.H.C.L. contributed equally to this work.

The authors declare no competing financial interests.

Correspondence should be addressed to either of the following: Takao K. Hensch, F. M. Kirby Neurobiology Center, Children's Hospital Boston, Harvard Medical School, 300 Longwood Avenue, Boston, MA 02115, E-mail: takao.hensch@childrens.harvard.edu; or Alain Prochiantz, Collège de France, Center for Interdisciplinary Research in Biology, F-75005 Paris, France. E-mail: alain.prochiantz@college-de-france.fr.

DOI:10.1523/JNEUROSCI.0394-12.2012

Copyright $\odot 2012$ the authors $\quad 0270-6474 / 12 / 329429-09 \$ 15.00 / 0$
}

plasticity outside the CP would thus be of great clinical value (Bavelier et al., 2010).

Normal CP opening corresponds to the maturation of local inhibitory circuits (Hensch, 2005) driven primarily by perisomatic, large-basket connections. These fast-spiking GABA neurons express parvalbumin (PV) and become enwrapped by perineuronal nets (PNNs) with age. PV cell maturation and $\mathrm{CP}$ timing are experience dependent: dark rearing from birth prevents V1 activation, delays PNN formation (Pizzorusso et al., 2002), and pushes plasticity onset into adulthood (Mower, 1991; Fagiolini et al., 2003). Artificially promoting PV cell function in the dark by benzodiazepine infusion (Iwai et al., 2003) or the overexpression of brain-derived neurotrophic factor (Gianfranceschi et al., 2003) can counteract the absence of vision.

Chondroitinase $\mathrm{ABC}$ (ChABC) digests glycosaminoglycan (GAG) side chains of chondroitin sulfate proteoglycans (CSPGs). The consequent destruction of CSPG-rich PNN structures in adult $\mathrm{V} 1$ reactivates ocular dominance $(\mathrm{OD})$ plasticity and restores visual acuity (Pizzorusso et al., 2002, 2006). This suggests that PNNs containing GAGs may place a "brake" on plasticity in $\mathrm{V} 1$ and beyond, including the barrel cortex, amygdala, and songbird brain (Balmer et al., 2009; Gogolla et al., 2009b; Nowicka et al., 2009). Exactly how PNN-like structures regulate brain function remains unknown.

We discovered that orthodenticle homeobox protein 2 (Otx2) endogenously coordinates PV cell maturation and, hence, the timing of the CP for OD in mouse V1b (Sugiyama et al., 2008). Moreover, the normal accumulation of Otx2 in PV cells is not 
due to cell-autonomous synthesis but to Otx 2 transfer from other areas. Otx2 persists throughout life in PV cells, and its capture is dependent on visual input (Sugiyama et al., 2008). Surprisingly, when Otx2 protein is exogenously infused into V1, it, too, localizes primarily in these cells, suggesting the existence of specific binding sites.

In the developing brain, homeoprotein intercellular transfer influences cell migration (Di Lullo et al., 2011), axon guidance (Brunet et al., 2005; Stettler et al., 2012), and retinotectal patterning (Wizenmann et al., 2009). Homeoprotein transfer is imparted by secretion and internalization motifs present in the highly conserved homeodomain (Joliot and Prochiantz, 2004). Yet, how homeoproteins recognize their target cells is unknown.

Here, we identify an Otx2 motif with high affinity for chondroitin-6-sulfates mediating Otx2 binding to PNNs. Infusing a peptide mimicking this GAG-binding site blocks Otx2 transfer into V1b in vivo, restores visual cortical plasticity in mature mice, and rescues cortical acuity in amblyopic mice. We propose that PNNs persistently maintain a nonpermissive state for plasticity beyond the CP by perpetually sustaining Otx 2 transfer above a critical threshold within PV cells, which themselves must be plastic for a CP to arise (Yazaki-Sugiyama et al., 2009).

\section{Materials and Methods}

Animals. Mature male C57Bl/6 mice (age range, P61-P150) were used throughout the study.

Protein production. The Alanine-Alanine (AA)-Otx2 protein bearing the substitution R36A, K37A was obtained by site-directed mutagenesis. Both human Otx2 and AA-Otx2 proteins have an $\mathrm{N}$-terminal 6xHis-tag. Details concerning the constructions are available on request. Mouse En2, human Otx2, and AA-Otx2 (R36A, K37A substitutions) recombinant proteins were produced in bacteria and purified on nickel-charged HiTrap Chelating Sepharose columns (GE Healthcare) according to manufacturer's instructions and assessed by SDS-PAGE. Proteins were stored at $-80^{\circ} \mathrm{C}$ in $20 \mathrm{~mm}$ HEPES, $\mathrm{pH} 8,500 \mathrm{~mm} \mathrm{NaCl}$ supplemented with $10 \%$ glycerol. Before use, glycerol was removed by dialysis against 20 mм HEPES, $\mathrm{pH} 8,500 \mathrm{~mm} \mathrm{NaCl}$. FITC labeling was performed as previously described (Joliot et al., 1991a).

Production of alkaline phosphatase fusion proteins. To generate alkaline phosphatase (AP)-tagged fusion constructs, cDNA encoding for Otx2 were subcloned between the XhoI and XbaI sites of the pAPtag- 5 vector (GenHunter). AP-tagged truncations were obtained by PCR, where AP$\mathrm{NtHD}$ corresponds to Otx2 (1-98) and AP-HD (AP fusion with the Otx2 homeodomain alone) corresponds to Otx2 (38-98). The R36A, K37A Otx2 point mutant was obtained by using the QuikChange II mutagenesis kit (Stratagene). Sequences are available on request. For production of AP-tagged fusion proteins, HEK 293 cells were plated in DMEM, 10\% fetal bovine serum (FBS) (Invitrogen) supplemented with penicillin/ streptomycin. Cells were transfected with the various AP-tagged constructs by Lipofectamine 2000 (Invitrogen) overnight in DMEM, 10\% FBS. After $48 \mathrm{~h}$, supernatants were collected, controlled by Western blotting and AP-tagged protein was quantified by measuring phosphatase activity with the soluble AP substrate $p$-nitro-phenyl phosphate (SigmaAldrich) before freezing at $-80^{\circ} \mathrm{C}$. AP activity measurements ensured the same amount of AP fusion protein was used in each experiment.

Protein and ChABC injection. Recombinant homeoproteins labeled with FITC and mixed with polysialic acid (PSA; $2.5 \mathrm{mg} / \mathrm{ml}$ ) were injected into P60 mice posterior cortex using a Hamilton syringe coupled to an electronic injection device. Injections were performed at three different sites encompassing V1. Coordinates for V1 injections were, with respect to lambda: $1.5 \mathrm{~mm}$ lateral; $2.5 \mathrm{~mm}$ lateral and $1.5 \mathrm{~mm}$ anterior; $4 \mathrm{~mm}$ lateral. For each location, $0.4 \mu \mathrm{l}$ of protein solution was slowly delivered $(0.05 \mu \mathrm{l} / \mathrm{min})$ at two different depths (300 and $500 \mu \mathrm{m}$ from the pial surface). One hour after injection, the mice were perfused transcardially with PBS followed by $4 \%$ paraformaldehyde (PFA) prepared in PBS. Brain coronal sections $(40 \mu \mathrm{m})$ were obtained using a vibratome (Microm) and then were processed for immunostaining. Biotinylated pep- tides $(250 \mu \mathrm{g} / \mathrm{ml})$ were infused in presence of PSA $(2.5 \mathrm{mg} / \mathrm{ml})$, into P60 mice V1, using micro-osmotic minipumps (Alzet). Animals were either processed for in vivo recording or perfused for immunostaining on brain sections. ChABC ( $50 \mathrm{U} / \mathrm{ml}$ in $0.1 \%$ BSA; Sigma-Aldrich) or vehicle solution were injected into the right or left hemisphere, respectively, of P60 mice using the same injection procedure described above. After $7 \mathrm{~d}$ postinjection, mice were processed for in vivo recording or otherwise perfused for immunostaining on brain sections $(3,7$, or $21 \mathrm{~d}$ after the treatment).

Immunostaining. Sections were incubated with primary antibodies overnight and Alexa Fluor-conjugated secondary antibodies for $1 \mathrm{~h}$. The following primary antibodies were used: anti-Otx2 [rat polyclonal, 1/200 (Sugiyama et al., 2008)] and anti-PV [mouse monoclonal, 1/500 (SigmaAldrich)]. Secondary antibodies were used as follows: anti-rat Alexa Fluor 488 [1/2000 (Invitrogen)] and anti-mouse Alexa Fluor 546 [1/2000 (Invitrogen)]. Alexa Fluor 633-conjugated streptavidin (Molecular Probes) was used for biotinylated peptide detection. Wisteria floribunda agglutinin (WFA) was either biotinylated [1/100 (Sigma-Aldrich)] or FITC conjugated [1/100 (Vector Laboratories)]. Immunostained sections were mounted using Fluoromount medium (Southern Biotechnology), and images were acquired using a Leica SP5 confocal microscope.

Binding on frozen sections. Cryosections $(20 \mu \mathrm{m})$ from fresh-frozen adult brains were mounted on glass slides and equilibrated at $-20^{\circ} \mathrm{C}$ for $30 \mathrm{~min}$. The sections were then fixed for $10 \mathrm{~min}$ by immersion in methanol $\left(-20^{\circ} \mathrm{C}\right)$, rinsed three times in PBS supplemented with $4 \mathrm{mM} \mathrm{MgCl}_{2}$ (W buffer), and blocked for $1 \mathrm{~h}$ in W buffer supplemented with 10\% FBS. The slides were then incubated with AP-tagged proteins for $2 \mathrm{~h}$ at room temperature in a humidified chamber, washed five times with $\mathrm{W}$ buffer, and fixed for $2 \mathrm{~min}$ at room temperature using a solution containing 50 mM HEPES, pH 7, 60\% acetone, and 4\% PFA. Endogenous alkaline phosphatases were inactivated by heating the slides at $65^{\circ} \mathrm{C}$ for $2 \mathrm{~h}$. The slides were finally rinsed twice in PBS before AP staining (NBT/BCIP color substrate; Promega). For enzymatic treatment, cryosections were fixed in methanol at $-20^{\circ} \mathrm{C}$ for $10 \mathrm{~min}$ and incubated $24 \mathrm{~h}$ with $\mathrm{ChABC}$ $(2 \mathrm{U} / \mathrm{ml})$ in a buffer containing $50 \mathrm{~mm}$ Tris, $\mathrm{pH} 8,40 \mathrm{~mm}$ sodium acetate, $0.1 \% \mathrm{BSA}$, and protease inhibitors (Roche).

Isothermal titration calorimetry. The heat flow resulting from the binding of peptides to GAGs was measured with high-sensitivity isothermal titration calorimetry using a Nano isothermal titration calorimetry (ITC) calorimeter (TA Instruments). Titrations were performed by successive injections of the GAG solution (concentration varying between 10 and $200 \mu \mathrm{M}$ ) into the calorimeter cell containing the peptide solution (concentration $100 \mu \mathrm{M}$ ). The experiments were performed at $37^{\circ} \mathrm{C}$. Data analysis was performed using the program NanoAnalyze provided by TA Instruments.

Single-unit electrophysiology in vivo. Electrophysiological recordings were performed under pentobarbital/chlorprothixene anesthesia using standard techniques (Gordon et al., 1996; Mataga et al., 2004). Five to seven single units were recorded for each mouse across the mediolateral axis (spaced at $>200 \mu \mathrm{m}$ intervals) of primary visual cortex to map the monocular and binocular zones and avoid sampling bias. Responses from cells were assigned ocular dominance scores using a seven-point classification scheme (Wiesel and Hubel, 1963; Gordon and Stryker, 1996). Ocular dominance in the binocular zone from each mouse was calculated as a contralateral bias index $(\mathrm{CBI})$ :

$$
\left[\left(n_{1}-n_{7}+2 / 3\left(n_{2}-n_{6}\right)+1 / 3\left(n_{3}-n_{5}\right)+N\right] / 2 N,\right.
$$

where $N=$ total number of cells and $n_{x}=$ number of cells corresponding to an ocular dominance score of $x$. This weighted average of the bias toward one eye or the other takes values from 0 to 1 for complete ipsilateral or contralateral eye dominance, respectively. Monocular deprivation consisted of eyelid suture under isoflurane anesthesia; in some cases, the suture was reopened to test for recovery (Morishita et al., 2010).

Visual evoked potentials. Transient visual evoked potentials (VEPs) in response to abrupt contrast reversal $(100 \%, 1 \mathrm{~Hz})$ over a range of spatial frequencies $(0.01-0.6$ cycles/degree) were bandpass filtered (0.1-100 $\mathrm{Hz}$ ), amplified, and fed to a computer for analysis. In brief, at least 20 events were averaged in synchrony with the stimulus contrast reversal. 
A

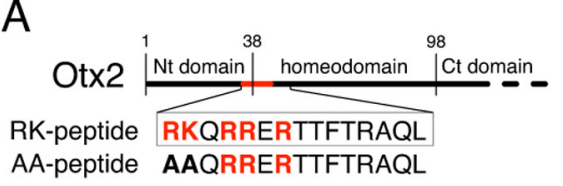

B
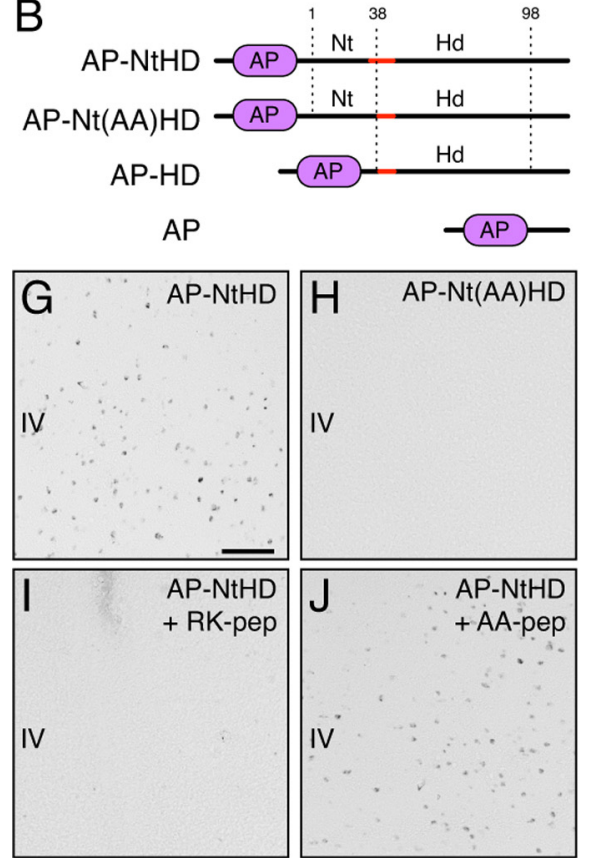
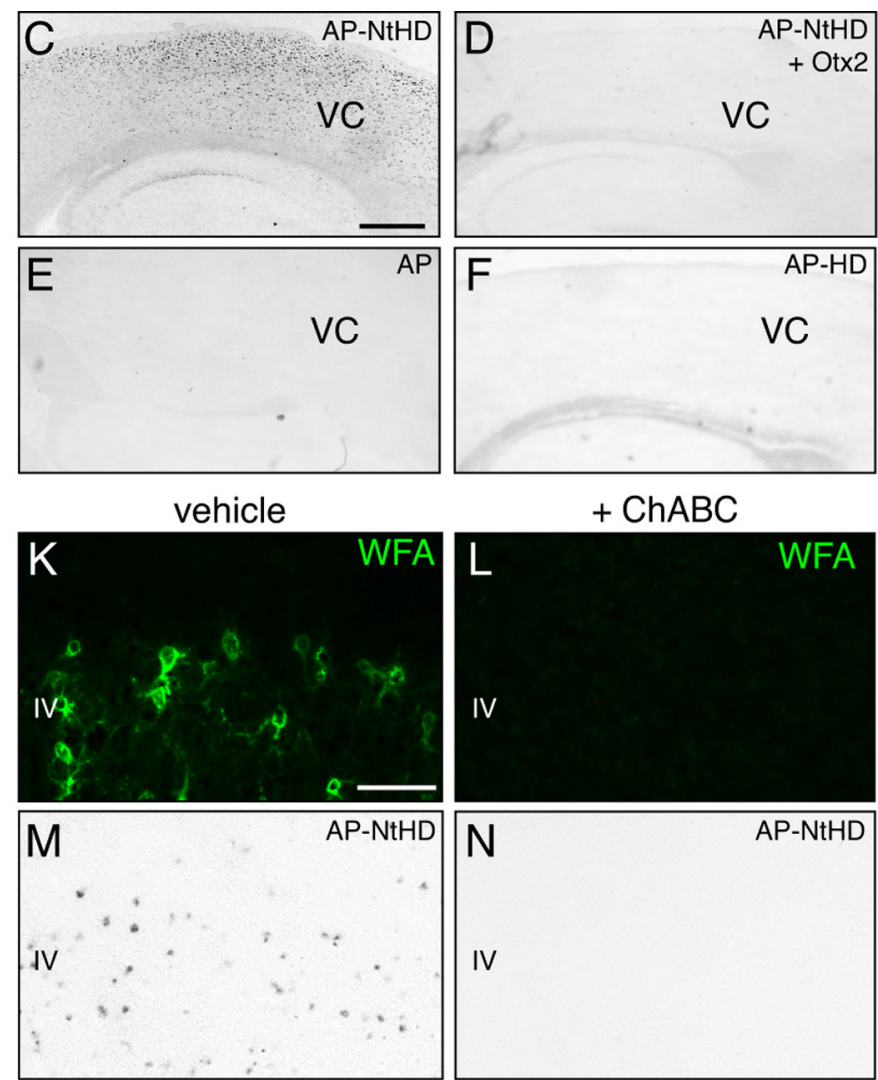

Figure 1. An 0tx2 motif necessary for binding to cortical sections. $A$, Putative GAG-binding motif (in red) in the 0tx2 N-terminal region bears an RK doublet just before the homeodomain. RK and AA peptide sequences are indicated. $B$, Schematic representation of AP fusion proteins used in binding experiments: AP-NtHD contains amino-acids 1-98 including the RK doublet and homeodomain; AP-Nt(AA)HD, in which the RK doublet is mutated to an alanine doublet; and AP-HD composed of AP fused directly to the homeodomain (aa 38 -98) without the RK doublet. Nonfused AP was used as a negative control. $\boldsymbol{C}, \boldsymbol{E}, \boldsymbol{F}, \mathrm{AP}$ staining on fresh-frozen sections reveals AP-NtHD (C) but not AP (E) or AP-HD $(\boldsymbol{F})$ binding to cells in the posterior cortex (V1). $\boldsymbol{D}$, Full-length 0tx2 disrupts AP-NtHD cortical binding (D). $\boldsymbol{G}, \boldsymbol{H}$, Higher magnification of V1 sections shows AP-NtHD binding ( $\boldsymbol{G})$ but not AP-Nt(AA)HD binding $(\boldsymbol{H})$. $\boldsymbol{I}, \boldsymbol{J}$, RK $(\boldsymbol{I})$, but not AA $(\boldsymbol{J})$, peptide antagonizes AP-NtHD binding. $\boldsymbol{K}-\boldsymbol{N}$, ChABC treatment of frozen sections abolishes WFA staining $(\boldsymbol{K}, \boldsymbol{L})$ and prevents AP-NtHD binding $(\boldsymbol{M}, \boldsymbol{N})$. Scale bars: (in $\boldsymbol{C}) \boldsymbol{C}-\boldsymbol{F}, 350 \mu \mathrm{m}$; (in $\boldsymbol{G}) \mathbf{G}-\boldsymbol{J}, 100 \mu \mathrm{m}$; (in $\boldsymbol{K}) \boldsymbol{K}, \boldsymbol{L}, 100 \mu \mathrm{m}$.

Cortical acuity was obtained by extrapolation to zero amplitude after correction of noise level.

\section{Results}

\section{An Otx 2 motif binds to PNNs in mouse V1}

Mature PV cells are ensheathed by PNNs (Härtig et al., 1999) that contain extracellular matrix factors, including cell-adhesion molecules, hyaluronic acids, and CSPGs (Berardi et al., 2004). Plant lectins such as WFA bind PNNs with high affinity for the negative charges of $N$-acetyl-D-galactosamine. Homeodomains carry a net positive charge and can bind to negatively charged PSA of embryonic NCAM at the cell surface (Joliot et al., 1991b). In our initial experiments performed at P19 (Sugiyama et al., 2008), we first preincubated homeoproteins with PSA to avoid their immediate internalization at the infusion site and to allow diffusion. We therefore hypothesized that specific Otx 2 capture by PV cells was due to the presence of higher affinity binding sites, possibly GAGs specifically expressed by PV cells as part of their PNNs.

Such specific recognition of PNN sugars by Otx2 supposes the presence of a GAG binding domain in the Otx2 sequence. We postulated that Otx 2 might contain a specific recognition domain for sugar epitopes on the surfaces of PV cells. Examination of the Otx2 primary sequence revealed a consensus motif for basic GAG binding within the N-terminal region (Fig. 1A). Notably, just before the highly conserved homeodomain resides an RK doublet considered crucial for sugar-binding motifs (Cardin and Weintraub, 1989). To study the interaction of this Otx2 domain with the surface of cortical cells, we turned to binding assays on freshfrozen brain sections using AP fusion proteins (Cheng and Flanagan, 1994).

The AP-NtHD fusion protein, which corresponds to the $\mathrm{N}$-terminal portion of Otx 2 that includes the RK doublet and the full homeodomain (Fig. $1 \mathrm{~B}$ ), was found to bind a subset of cells in the posterior mouse neocortex (Fig. $1 C, G$ ). Specificity of this interaction was confirmed by competition with nontagged, fulllength Otx2 (Fig. 1D) and the absence of binding of AP alone (Fig. $1 E$ ). Interestingly, AP-HD did not bind to fresh-frozen sections, suggesting that the RK doublet plays a crucial role in this binding of Otx2 (Fig. $1 F)$.

To confirm the importance of the RK doublet in cell surface binding, we used an AP-fusion protein in which this doublet was replaced with alanines (AP-Nt(AA)HD). This mutation abolished the binding (Fig. $1 H$ ) and prompted us to design a small 15 aa peptide (RKQRRERTTFTRAQL) corresponding to the putative GAG-binding motif (Fig. $1 A$ ). The RK peptide was able to chase AP-NtHD binding (Fig. $1 I$ ), whereas an AA peptide (in which the RK doublet was replaced by alanines) was unable to outcompete AP-NtHD binding on fresh-frozen sections (Fig. $1 \mathrm{~J}$ ).

These findings support the RK doublet motif as requisite for the specific recognition of PV cells by Otx2. We therefore tested whether the observed Otx 2 binding could be altered by the disruption of PNNs. After 24 h of ChABC treatment of fresh-frozen 
sections, AP-NtHD was no longer able to bind to cortical cells (Fig. $1 \mathrm{~K}-\mathrm{N}$ ). In contrast, heparinase treatment failed to prevent Otx2 binding (data not shown). Together, these results indicate that CSPG recognition by the RK doublet of Otx2 is essential for the proper binding of this fragment to occur.

To further investigate the properties of this small Otx2 fragment, we used ITC to directly measure the affinity of the RK peptide for distinct GAGs (Table 1). The RK peptide bound strongly to CS-D and CS-E, had a lower affinity for CS-C and heparin, and showed no measurable binding to CS-A. Thus, the RK peptide binds preferentially to chondroitin sulfates carrying a sulfate on carbon 6 (CS-D and CS-E). Interestingly, we found that the AA peptide did not bind CS-D or heparin, confirming the importance of the RK doublet. Given that an absence of AA binding could be explained by a charge difference (net charge of 5 for RK peptide and of 3 for AA peptide), we further designed a scrambled peptide (RTQTRFRTRARLEQK) with the same amino acid composition as the RK peptide but found that it had a consistently lower affinity for heparin and CS-D when compared to RK peptide.

Together, these results strongly suggest that Otx2 has a strong affinity for PNNchondroitin sulfates (probably sulfated on carbon 6) and that the RK doublet is part of the recognition motif.

\section{Persistent accumulation of Otx 2 into PV cells by $\mathrm{PNN}$ interaction}

We first confirmed whether PNNs and endogenous Otx 2 colocalize in adult V1b, as observed during the CP (Sugiyama et al., 2008). Posterior brain sections from P60 mice were labeled with both the lectin WFA and an antibody directed against Otx2. We found a strong association between endogenous Otx2 and PNNs (Fig. $2 A-C)$. A large proportion of cells containing Otx2 were indeed enwrapped by PNNs $(68.4 \pm 3.2 \%)$, whereas most WFA-labeled cells contained Otx2 (84.2 $\pm 3.7 \%)$.

To test the importance of the RK doublet for PV cell recognition in vivo, we compared the localization of injected fulllength FITC-Otx2 protein with that of FITC-AA-Otx2 protein in which the RK doublet was replaced by an alanine doublet. As illustrated in Figure 2D-L and quantified in Figure $2 M$, the percentage of FITC-AA-Otx2-positive cells enwrapped by WFA staining $(27.2 \pm 1.5 \%)$ was significantly less than that observed with wild-type FITC-Otx2 (51.3 $\pm 2.8 \%)$. Engrailed-2 (En2), an unrelated homeoprotein control, showed a pattern $(33.1 \pm 2.3 \%$ internalization by WFA-positive cells) (Fig. 2I-K) similar to that of AA-Otx2. These results demonstrate that the RK motif of Otx 2 participates in the specific recognition of Otx2 by PNNs and allows the preferential accumulation of the homeoprotein within layer IV PV cells in vivo.

M
Table 1. Binding of RK peptide and its two variants to different GAGs

\begin{tabular}{lll}
\hline Ligand & GAG & Dissociation constant $K_{\mathrm{d}}(\mathrm{nm})$ \\
\hline RK peptide & CS-A & No binding \\
& CS-C & $159 \pm 84$ \\
& CS-E & $54.5 \pm 22.5$ \\
& CS-D & $17.9 \pm 5.7$ \\
Scb peptide & Heparin & $193 \pm 21$ \\
& CS-D & $95.5 \pm 9.5$ \\
AA peptide & Heparin & $505 \pm 161$ \\
& CS-D & No binding observed \\
& Heparin & No binding observed \\
\hline
\end{tabular}

Dissociation constant of RK, $A A$, or $S c b$ peptide for various commercial chondroitin sulfates and heparin determine by ITC $\left(37^{\circ} \mathrm{C}\right)$. Highest RK peptide affinity for CS-D and CS-E suggests the importance of sulfation on carbon 6 . Scb has lower affinity for CS-D, indicating sequence-specific (not charge-specific) recognition. AA peptide shows no affinity.
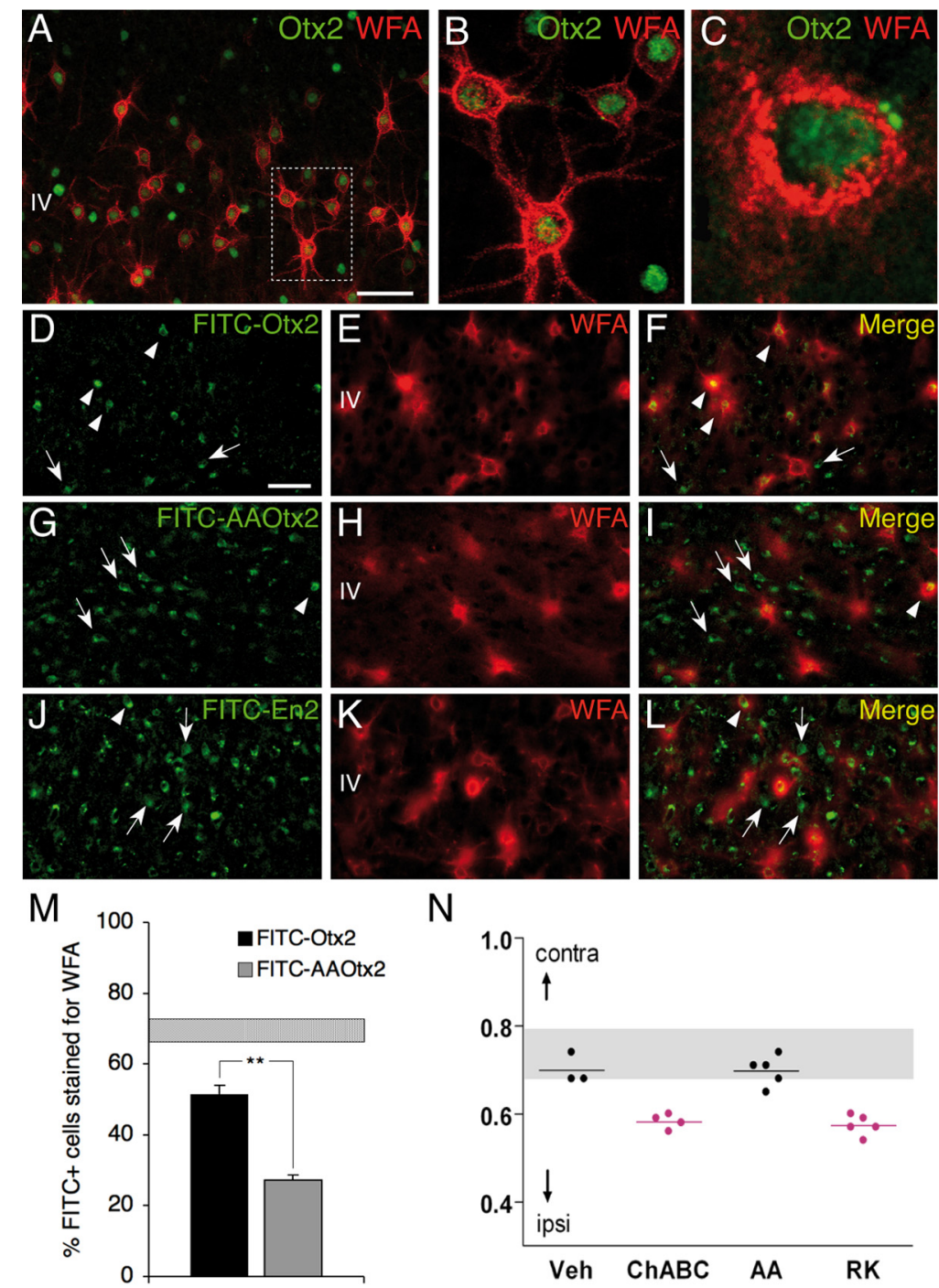

N

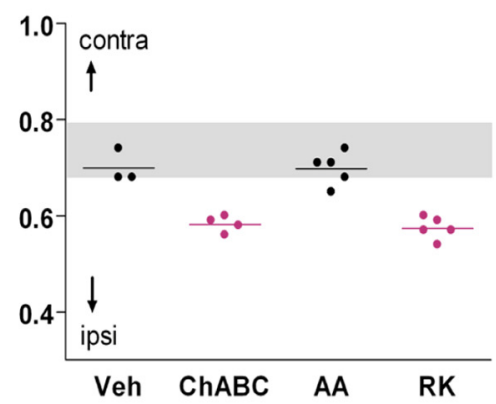

Figure 2. Preferential $0 \mathrm{t} \times 2$ capture by PV cells requires the RK doublet. $A-C$, Codetection of WFA and $0 \mathrm{t} \times 2$ in layer IV of P60 mouse V1b. Inset in $\boldsymbol{A}$ is magnified in $\boldsymbol{B}$. C, Staining performed under nonpermeabilizing conditions reveals extracellular/membranous 0 tx2 staining. $\boldsymbol{D}, \boldsymbol{G}, \boldsymbol{J}$, Distribution of FITC-labeled 0tx2 (D), AA-0tx2 (G), and En2-FITC $(\boldsymbol{J})$ recombinant proteins after injection into P60 mice. $\boldsymbol{E}, \boldsymbol{F}, \boldsymbol{H}, \boldsymbol{I}, \boldsymbol{K}, \boldsymbol{L}$, WFA detection $(\boldsymbol{E}, \boldsymbol{H}, \boldsymbol{K})$ and merged FITC-0tx2 images reveal preferential 0 tx2 capture by WFA-labeled cells $(\boldsymbol{F})$ compared with AA-0tx2 $(\boldsymbol{I})$ and En2 $(\boldsymbol{L})$. Arrowheads, Double-stained cells; arrows, FITC-positive cells not stained with WFA. Scale bars: $\boldsymbol{A}, 50 \mu \mathrm{m}$; (in $\boldsymbol{D}) \boldsymbol{D}-\boldsymbol{L}, 50 \mu \mathrm{m}$. $\boldsymbol{M}$, Percentage of FITC-positive cells costained for WFA after FITC-0tx2 or AA-0tx2 injection. Striped bar, endogenous percentage of 0tx2-positive cells costained for WFA (mean \pm SEM). $N, C B I$ of single-unit recordings from mice treated with ChABC, RK, or AA peptide after a period of brief $M D(4 \mathrm{~d})$ in adulthood. Both ChABC and RK peptide infusion similarly reactivate visual cortical plasticity (decrease of (BI compared with non-MD), which is not typically seen in saline- or AA peptide-infused adult mice. 


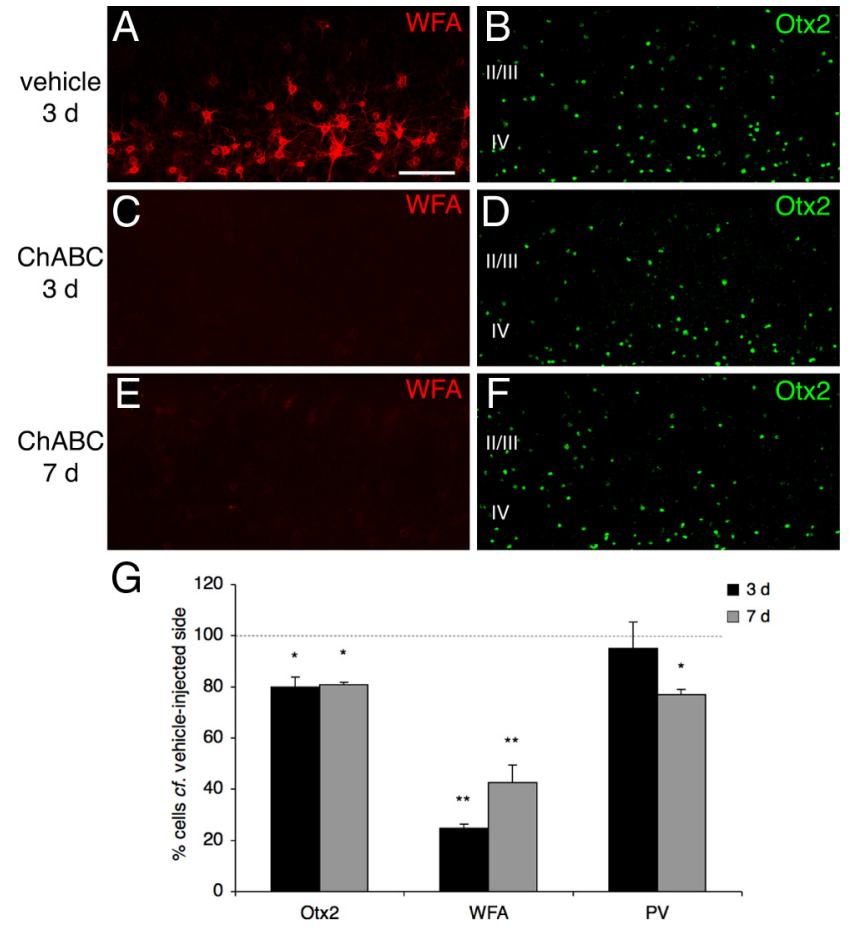

Figure 3. PNNs facilitate the preferential capture of endogenous 0 tx2 by PV cells. $A, C, E$, ChABC injection into adult V1 disrupts PNNs, as revealed by the near absence of WFA staining at 3 or 7 d postinjection $(\boldsymbol{C}, \boldsymbol{E})$ compared with the contralateral, vehicle-injected side $(\boldsymbol{A}) . \boldsymbol{B}, \boldsymbol{D}, \boldsymbol{F}$, PNN hydrolysis decreases the number of 0tx2-positive cells, respectively, at $3 \mathrm{~d}(\boldsymbol{D})$ and $7 \mathrm{~d}(\boldsymbol{F})$ postinjection compared with the contralateral, vehicle-injected side $(\boldsymbol{B})$. $\boldsymbol{G}$, Percentages of Otx2-, WFA-, and PV-positive cells in supragranular layers of V1b (ChABC-treated compared with the contralateral vehicle side) 3 and $7 \mathrm{~d}$ postinjection $\left({ }^{*} p<0.05,{ }^{* *} p<0.01\right.$, paired $t$ test; four mice per group; $700 \times 200 \mu \mathrm{m}$ area). Error bars indicate SEM. Scale bar: (in $\boldsymbol{A}$ ) $\boldsymbol{A}-\boldsymbol{F}, 100 \mu \mathrm{m}$.

Because WFA-labeled cells represent only a small percentage of all neurons, we further determined the percentage of NeuNpositive cells also stained with FITC. We found that FITC-Otx2, FITC-AAOtx2, and FITC-En2 are, respectively, internalized by $1.4 \pm 0.2 \%, 3.6 \pm 0.2 \%$, and $2.4 \pm 0.002 \%$ of WFA-negative cells. This result strongly suggests that the twofold difference of Otx2 internalization by WFA-labeled cells following the RK to AA mutation is due to a twofold increase in the percentage of WFAnegative cells that capture the protein. However, a large number of neurons do not capture the proteins or capture them below detection levels.

To address whether PNNs are required for endogenous Otx2 accumulation into V1b PV cells, we injected ChABC into adult mouse $\mathrm{V} 1$, then examined various markers after treatment. By $3 \mathrm{~d}$, in cortical supragranular layers, there was a marked and significant decrease, compared with the vehicle-injected contralateral hemisphere, in the number of both WFA-positive (Fig. $3 A, C, G ; 24.8 \pm 1.4 \%$ ) and Otx2-positive (Fig. 3B,D,G; $79.9 \pm$ $3.8 \%$ ) cells. PV expression was not modified significantly (94.9 \pm $10.4 \%)$. Seven days postinjection, the number of WFA-labeled cells partially recovered (Fig. $3 E, G ; 42.5 \pm 6.9 \%$ ), whereas the number of Otx2-positive cells (Fig. $3 F, G ; 80.8 \pm 0.8 \%$ ) remained as low as at $3 \mathrm{~d}$. Moreover, by this stage, PV labeling also exhibited a marked decrease $(77.1 \pm 1.9 \%)$, suggesting that Otx2 regulates PV expression in the adult.

Thus, the localization of endogenous Otx2 was disrupted by the removal of PNNs surrounding PV cells. Under these treatment conditions, ChABC has been reported to reactivate visual
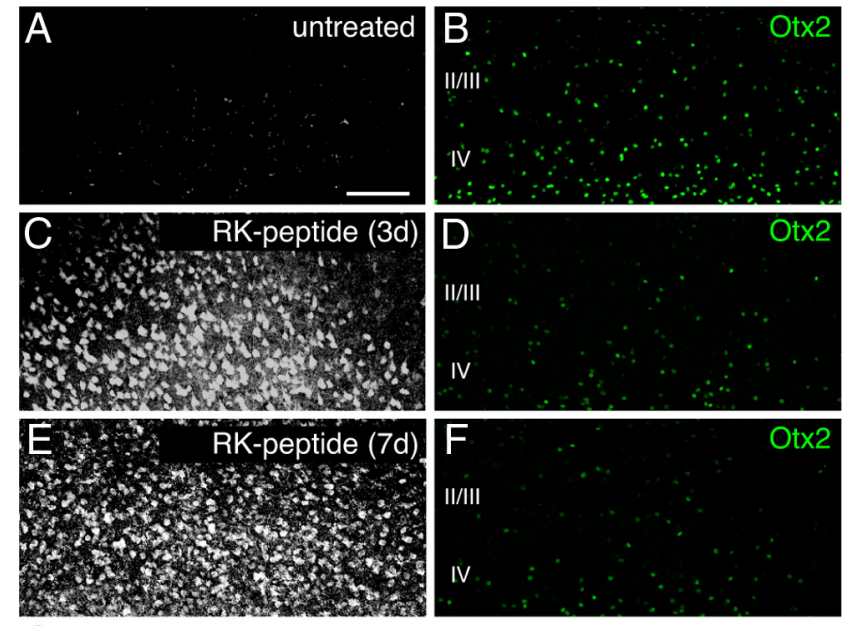

G

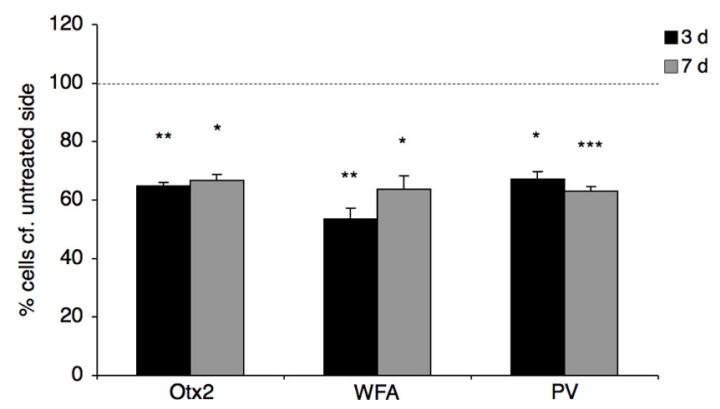

Figure 4. RK peptide reduces endogenous $0 \mathrm{t} \times 2$ localization in V1. $\boldsymbol{B}, \boldsymbol{D}, \boldsymbol{F}, 0 \mathrm{tx2}$ immunostaining in layers II-IV of V1b from an untreated $\mathrm{P} 60$ mouse $(\boldsymbol{B})$ or a P60 mouse infused for $3 \mathrm{~d}(\boldsymbol{D})$ or $7 \mathrm{~d}(\boldsymbol{F})$ with biotinylated RK peptide. $\boldsymbol{A}, \boldsymbol{C}, \boldsymbol{E}$, Peptides revealed by Alexa Fluor 633-conjugated streptavidin. G, Percentages of Otx2-, WFA-, and PV-positive cells (infused compared with contralateral, untreated side) in supragranular layers of $\mathrm{V} 1 \mathrm{~b}\left({ }^{*} p<0.05,{ }^{* *} p<0.01,{ }^{* * *} p<\right.$ 0.001 , paired $t$ test; four mice per group; $700 \times 450 \mu \mathrm{m}$ area). Error bars indicated SEM. Scale bar: (in $\boldsymbol{A}) \boldsymbol{A}-\boldsymbol{F}, 100 \mu \mathrm{m}$.

plasticity in adult rats (Pizzorusso et al., 2002). Given that Otx2 normally signals CP onset and is continually maintained thereafter into adulthood (Sugiyama et al., 2008), we postulated that the removal of PNNs might enable plasticity by reducing Otx2 transfer. Namely, if PV cells were rejuvenated by Otx2 removal, V1b could be reset to a CP state (Morishita and Hensch, 2008). To explore this hypothesis, we first had to validate whether adult OD plasticity after ChABC treatment also occurs in mouse V1b. Responses to visual stimuli were measured in the binocular zone of ChABC-injected mice by extracellular single-unit recording and were summarized by the CBI (Gordon and Stryker, 1996; Hensch et al., 1998), where 0 represents complete ipsilateral eye dominance and 1 represents complete contralateral eye dominance. As first reported for rats (Pizzorusso et al., 2002), ChABC treatment also reactivated plasticity in the adult mouse V1b (Fig. $2 \mathrm{~J}$ ).

\section{Otx2 RK domain specifies PV cell recognition in V1}

Because the RK peptide reduces binding of Otx 2 in vitro and the $\mathrm{RK}$ doublet plays a role in the recognition of PV cells in vivo, we tested whether the peptide could block Otx2 transfer in vivo comparable to ChABC treatment. A biotinylated version of the RK peptide was infused into adult mouse V1 for 3 or $7 \mathrm{~d}$. As illustrated in Figure $4 A-F$, and quantified in Figure $4 G$, we observed in cortical supragranular layers of infused animals a rapid and marked decrease in the number of Otx2-positive cells compared with the untreated hemisphere (at $3 \mathrm{~d}: 64.9 \pm 1.1 \%$; at $7 \mathrm{~d}: 66.7 \pm$ $2.2 \%)$. In addition, blocking Otx 2 transfer induced a significant 

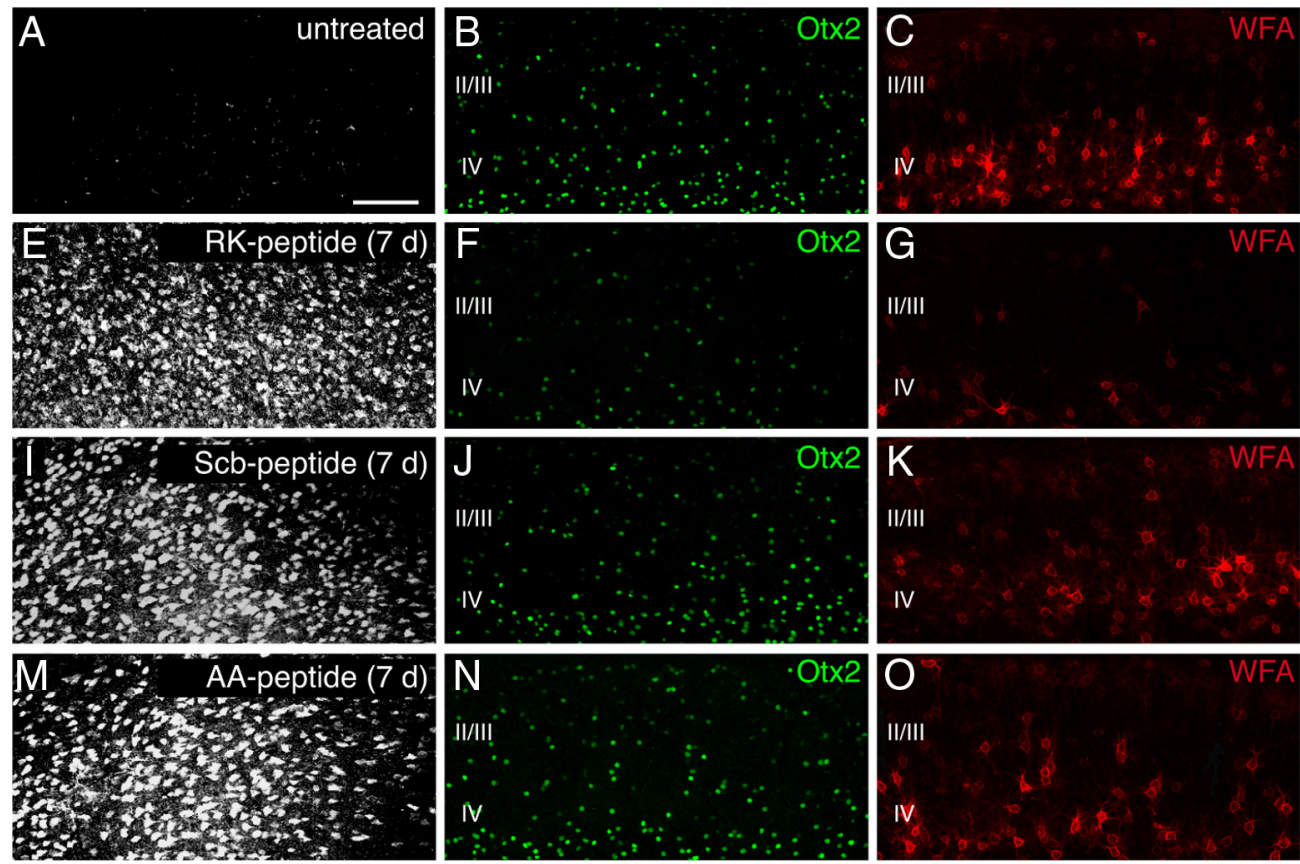
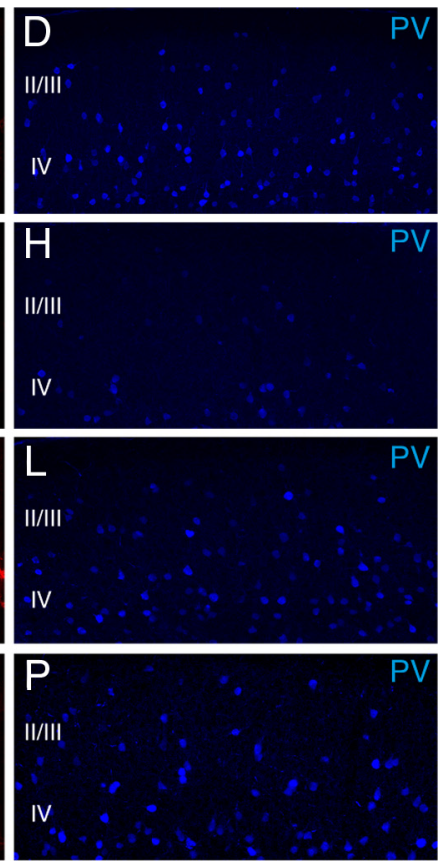

Figure 5. Specific, reversible control of PV cell 0tx2 content and maturational state by RK peptide. $A-P$, Immunostaining for 0 tx2, WFA, and PV in layers II-IV of V1b from P60 mice untreated $(\boldsymbol{A}-\boldsymbol{D})$ or infused for $7 \mathrm{~d}$, respectively, with RK $(\boldsymbol{E}-\boldsymbol{H}), \operatorname{Scb}(\boldsymbol{I}-\boldsymbol{L})$, or AA peptide $(\boldsymbol{M}-\boldsymbol{P}) . \boldsymbol{A}, \boldsymbol{E}, \boldsymbol{I}, \boldsymbol{M}$, Peptides revealed by Alexa Fluor 633-conjugated streptavidin. Scale bar: (in $\boldsymbol{A}) \boldsymbol{A}-\boldsymbol{P}, 100 \mu \mathrm{m}$.

loss of WFA and PV staining (at 3 d: WFA $53.6 \pm 3.5 \%$, PV $67.1 \pm 2.7 \%$; at 7 d: WFA $63.6 \pm 4.6 \%$, PV $63.1 \pm 1.6 \%)$ not seen at $2 \mathrm{~d}$ (WFA $90.5 \pm 5.7 \%$; PV $96.5 \pm 5.6 \%)$. Brief MD $(4 \mathrm{~d})$ of the contralateral eye during 1 week of RK (but not of AA) peptide infusion induced a CBI shift that was strikingly similar to that observed with ChABC injection (Fig. $2 J$ ).

In another series of experiments, we compared the effects of RK peptide with those of its two variants, the AA and the Scrambled RK (Scb) peptides. As shown in Table 1, the AA variant had no measurable affinity for CS-D, whereas Scb peptide retained some affinity ( $95.5 \mathrm{~nm}$ vs $17.9 \mathrm{~nm}$ for the RK peptide), suggesting an influence of both charge and sequence on GAG recognition. Figure 5 illustrates the respective effect of a $7 \mathrm{~d}$ infusion of the three peptides on the cortical localization of Otx2 and other markers. Only the RK peptide had an effect on PV and WFA signals. Notably, the Scb peptide failed to compete for Otx2 transfer and did not alter PNN or PV expression. Thus, RK peptide is specifically capable of disrupting Otx2 transfer in vivo (Fig. 6A).

Because the peptides are rapidly removed from the parenchyma, we verified whether their effects were reversible. Figure $6 B$ compares reversibility after ChABC treatment and RK peptide infusion. As mentioned previously (Fig. 3), $7 \mathrm{~d}$ after a single ChABC injection, WFA binding site $(42 \pm 5 \%), \mathrm{PV}(72.5 \pm$ $5.6 \%)$, and Otx2 $(80.8 \pm 5.6 \%)$ signals were acutely reduced. However, with an additional $14 \mathrm{~d}$ (i.e., $21 \mathrm{~d}$ postinjection), WFA staining was nearly back to control levels $(84.6 \pm 4.6 \%)$, whereas Otx2 (104.4 $\pm 2.1 \%)$ and PV (103.2 $\pm 2 \%)$ staining had completely recovered. Despite low levels of RK peptide still present 1 week after a $7 \mathrm{~d}$ infusion, suggesting washout or degradation (data not shown), the number of Otx2-containing cells remained reduced.

Figure $6 B$ quantifies a set of experiments in which, following RK peptide infusion, the number of cells stained with the antiOtx2 antibody was severely reduced ( $18.3 \pm 3.3 \%$ of control) and those of WFA and PV were reduced to $53.8 \pm 6.5 \%$ and $64.7 \pm$ $4.2 \%$ of control, respectively. Seven days after stopping RK pep-
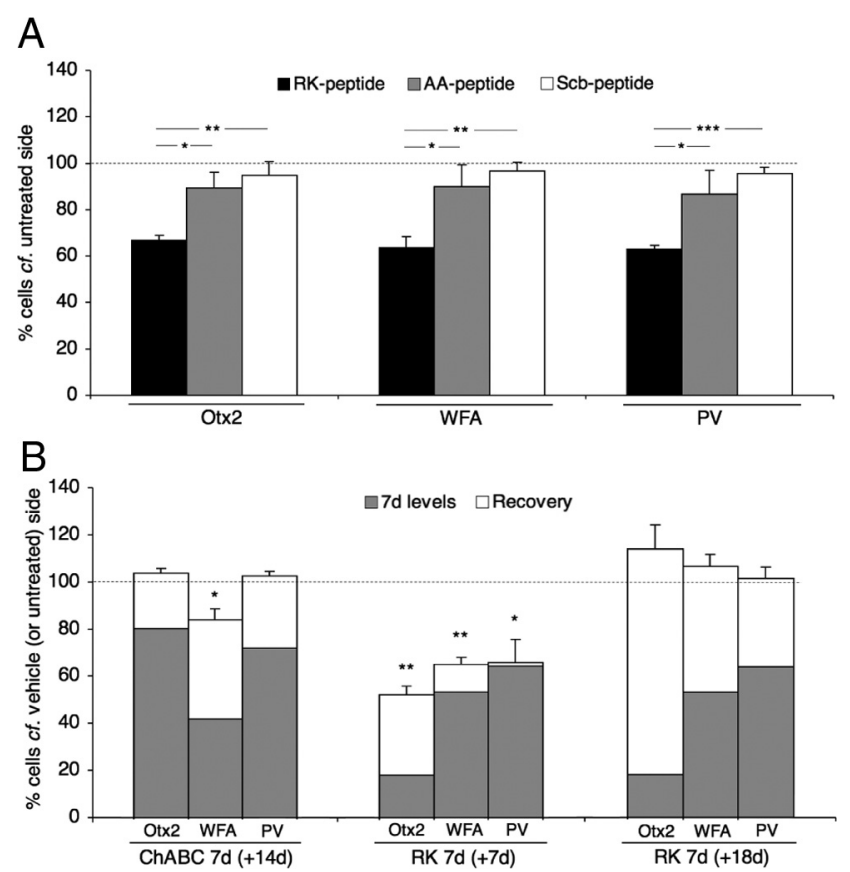

Figure 6. Quantification of RK peptide specificity and recovery. A, Percentages of Otx2-, WFA-, and PV-positive cells (infused compared with contralateral, untreated side) in supragranular layers of $\mathrm{V} 1 \mathrm{~b}\left({ }^{*} p<0.05,{ }^{* * *} p<0.001\right.$, paired $t$ test; four mice per group; $700 \times 450$ $\mu \mathrm{m}$ area). Error bars, SEM. B, Percentages of Otx2-, WFA-, and PV-positive cells (infused compared with contralateral, untreated side) in supragranular layers of $\mathrm{V} 1 \mathrm{~b}$. Gray bars, $7 \mathrm{~d}$ after $\mathrm{ChABC}$ injection or RK peptide infusion. Open bars, extended recovery period after $\mathrm{ChABC}$ treatment (ChABC 7d $+14 d$ ) or RK peptide infusion (RK 7d $+7 d$ and RK 7d $+18 d$ ), respectively.

tide infusion, recovery was partial $(52.6 \pm 3.7 \%, 65.6 \pm 2.9 \%$, and $66.3 \pm 9.8 \%$, respectively, for Otx2, WFA, and PV), requiring $>18 \mathrm{~d}$ of washout for total recovery $(115.2 \pm 10.5 \%, 107.8 \pm$ $5.3 \%$, and $102.7 \pm 4.9 \%$, respectively, for Otx2, WFA, and PV). We also found that recovery was limited in the dark $(69.8 \pm 2.3 \%$, 


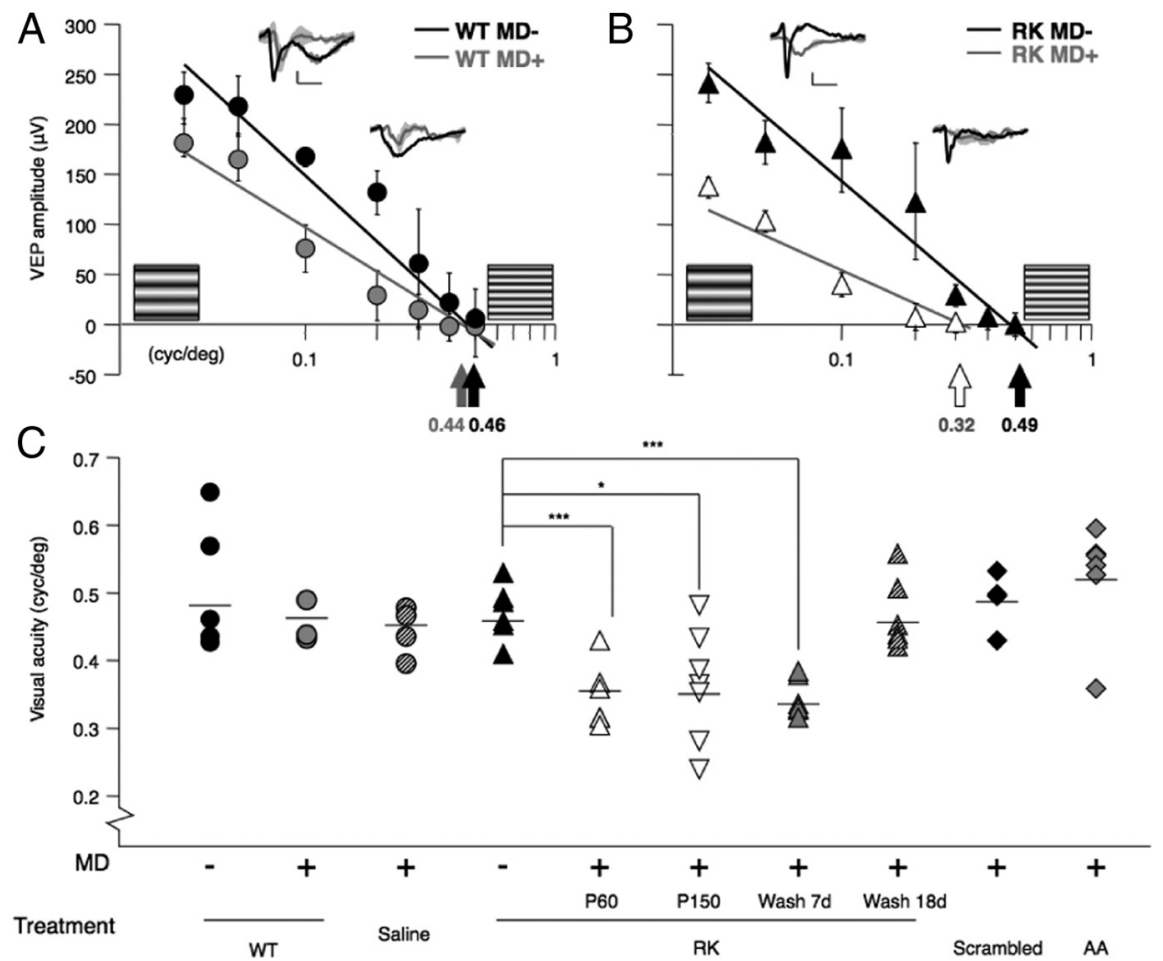

Figure 7. Reactivation of plasticity by RK peptide in adulthood: loss of cortical acuity by MD. $A$, No acuity loss after brief MD (4 d, gray line) compared with nondeprived wild-type (WT) animals (black line) by averaged VEP amplitudes (mean \pm SEM) of first negative peak (inset traces; scale: $20 \mathrm{mV}, 0.1 \mathrm{~s}$ ). $\boldsymbol{B}$, Significant acuity reduction upon brief MD (white symbols) paired with RK peptide infusion (black symbols) into adult mouse V1. C, Cortical acuity in adult WT mice is unaltered by brief MD (4d) paired with saline, Scb, or AA peptide. A brief window of plasticity persists $<18 \mathrm{~d}$ after RK peptide treatment ends. The mean value for each group is represented by a horizontal bar.

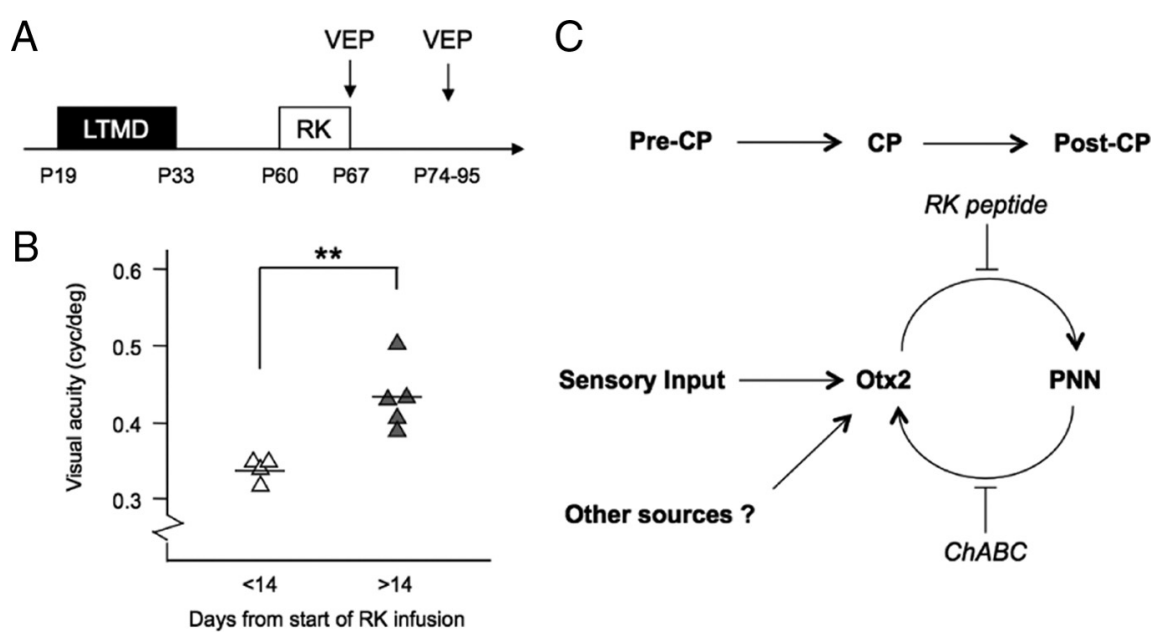

Figure 8. Functional recovery from amblyopia by RK peptide. $A$, Amblyopia rescue paradigm: long-term MD (LTMD) spanning the (P in mice (P19-P33) is followed by eye reopening and subsequent RK infusion (7 d) at P60. VEP recordings are performed at different stages after RK infusion to assess cortical acuity. $\boldsymbol{B}$, Amblyopic mice are not rescued by $7 \mathrm{~d}$ RK infusion alone (VEP at P67) but are significantly corrected after $>14 \mathrm{~d}$ of concurrent binocular vision (VEP at P74-P95; ${ }^{* *} p<0.01$, Student's $t$ test; five mice per group). C, Otx2 accumulation in PV cells driven by sensory experience (Sugiyama et al., 2008) and potentially other sources initially triggers a $C P$ for plasticity, which eventually closes as PNNs condense around them. This, in turn, maintains a stable post-CP state by persistently attracting 0tx2 throughout life in a positive feedback loop. Blocking 0tx2 transfer (RK peptide) or PNN removal $(\mathrm{ChABC})$ resets $\mathrm{PV}$ cells to reactivate $\mathrm{CP}$ plasticity.

$84.9 \pm 3.1 \%$, and $87.7 \pm 2.5 \%$, respectively, for Otx2, WFA, and PV) and thus was partially activity dependent. Thus, the rapid decrease in the number of Otx2-containing cells as early as $2 \mathrm{~d}$ after RK peptide infusion reflects reduced Otx 2 content rather than permanent loss by cell death. This suggests a potential therapeutic window for restoring juvenile plasticity to the adult brain.

\section{RK peptide regulates cortical acuity in adult V1}

To determine the clinical value of RK peptide, we directly measured cortical acuity in the mature mouse. Sine-wave gratings of ever higher spatial frequency were presented to anesthetized animals while recording VEPs from V1b (Morishita et al., 2010). As expected, brief MD failed to reduce cortical acuity past a CP (>P60) (Fig. 7A). Instead, a significant drop in acuity was produced by brief MD during a $7 \mathrm{~d}$ infusion of RK peptide (Fig. 7B). Given that residual plasticity may linger until P110 in mouse V1b (Lehmann and Löwel, 2008), we further confirmed the reopening of plasticity up to P150 (Fig. 7C). Across a panel of treatment conditions described above, only MD paired with RK peptide infusion or within a subsequent washout period of $<18 \mathrm{~d}$ resulted in changes to adult cortical acuity (Fig. $7 C)$. Neither Scb nor AA peptide treatment reactivated plasticity, consistent with their lack of effect on Otx2 transfer into cortical PV cells (Fig. 6A).

Thus, continuous Otx2 accumulation in PV cells may be necessary to sustain a state that limits further plasticity in adulthood. We therefore tested the possibility of rescue from amblyopia beyond the $\mathrm{CP}$ (Fig. 8). Mice were subjected to MD during their CP (from P19), and the deprived eye reopened (at P33) and was allowed to grow into adulthood ( $>$ P60). RK peptide or control was then infused into V1 for $7 \mathrm{~d}$ by osmotic minipump, and the cortical acuity of the originally deprived eye was measured using VEP recording at various time points after pumping ceased. Significant improvement of cortical acuity was observed $>14 \mathrm{~d}$ after the onset of RK peptide infusion (at P74-P95) (Fig. 8). This confirms a therapeutic window aligned with the transient window of cortical plasticity induced by RK peptide (Figs. 5-7).

\section{Discussion}

The function of PNNs has remained largely mysterious since their first description by Camillo Golgi more than a century ago (Celio and Blumcke, 1994; Härtig et al., 1999). We have found that the internalization of Otx2 by a subpopulation of cells in the neocortex (PV cells) is facilitated by the recognition of one or several sugar sequences in the PNN, probably enriched in chondroitin-6-sulfate moieties (CS-D, CS-E, or both). This recognition requires a short Otx2 
domain with GAG-binding molecular characteristics that can be antagonized in vivo to reduce endogenous Otx2 internalization and downregulate PV expression and WFA binding sites to reactivate plasticity in the binocular visual cortex (Fig. $8 C$ ). We thus propose that PNNs provide Otx2 binding sites facilitating internalization. This unexpected PNN function does not rule out other functions related (or not) to cortical plasticity.

Homeodomain and homeoprotein internalization is not believed to be receptor dependent, and the third helix of the homeodomain (Penetratin; Qbiogene), which is necessary and sufficient for internalization, does not bind a chiral receptor (Joliot and Prochiantz, 2004). However, negative charges are important for homeoprotein internalization, and the homeodomain alone shows a higher affinity for cells expressing specific sugars at their surfaces. In particular, Antennapedia is preferentially captured in vitro by neurons expressing $\alpha 2,8$-PSA (Joliot et al., 1991b). This absence of specificity in vitro does not mean that extracellular homeoproteins do not recognize specific cells in vivo, and our present data strongly suggest that GAG sequences may participate in this "sugar code" for homeoprotein recognition.

In fact, most studies indicate that the efficiency of internalization of these transduction proteins and peptides is increased by their interaction with complex sugars (Ziegler, 2008; Ziegler and Seelig, 2008). Here, we suggest that this recognition is specific, reminiscent of the mode of action of several morphogens and growth factors (e.g., FGF 1/2) that must bind a proteoglycan before they activate a transducing receptor (Jastrebova et al., 2006). In some cases, the diffusion of a morphogen requires it to be attached to complex sugars until it actually binds a receptor (Bulow and Hobert, 2006; Gallet et al., 2008).

In our homeoprotein infusion experiments, Otx2 internalization by PV cells results from an exchange of the protein between its carrier (PSA) and a binding site (the acceptor) at the cell surface. We demonstrate that an Otx2 domain of 15 aa participates in this recognition and that the replacement of an RK doublet by an AA doublet abolishes specificity. The importance of this short sequence is further supported by differences of in vitro affinities for specific sugars (Table 1) and by their distinct physiological effects in vivo. Indeed, when infused into the cortex, the three peptides localize in a similar nonspecific manner around the site of infusion. However, in contrast to the RK peptide, the AA and Scb peptides do not significantly change Otx2 accumulation inside PV cells and have no effect on the expression of PV or that of PNNs. We also noticed that the degree of reduced Otx2 accumulation by the RK peptide could vary between experiments (from 40 to $80 \%$ ) but was always higher than the reduction by ChABC ( $\sim 20 \%)$. Reactivation of plasticity was observed regardless of this variation.

We therefore propose that the Otx2 RK domain enables binding to an "acceptor site" containing a chondroitin-6-sulfate. Because GAG sulfation patterns determine most of their binding properties, the avidity of Otx2 for 6-sulfated CS is of particular interest. Indeed, in the rat posterior cortex, the amount of 6-sulfated GAG has been found to drop dramatically between P21 and adulthood (where they represent 3\% of the GAG) (Carulli et al., 2011). Moreover, very recent evidence suggests a developmental increase in the 4-sulfation/6-sulfation (4S/6S) ratio of CSPGs may be required for the accumulation of Otx2 (Miyata et al., 2012). Thus, the recognition of Otx 2 by PV cells might, at least in part, stem from the progressive refinement of the PNN sulfation profile.

Although we do not exclude the possibility that a glycoprotein could transduce a specific signal across the membrane, our pres- ent understanding of homeoprotein action (Brunet et al., 2005, 2007; Wizenmann et al., 2009) favors the idea of a non-cellautonomous regulation of translation and transcription by Otx2 after its internalization. The actual targets at both levels are presently under investigation and, once identified, will be analyzed at a functional level. Notably, both gain- and loss-of-function (Sugiyama et al., 2008; this study) indicate that Otx2 internalization enhances the expression of several markers of PV cell maturation, including PNN formation itself.

From a physiological point of view, the ongoing positive feedback of nascent PNNs attracting Otx2 for their own continued maintenance throughout life may serve to prevent plasticity in adulthood (Fig. 8C). Importantly, PV cells receive the most potent and direct input from thalamus (Erisir and Dreusicke, 2005; Cruikshank et al., 2007) and have themselves been shown to display a robust bidirectional plasticity that becomes limited with age (Yazaki-Sugiyama et al., 2009). Our results provide a mechanistic explanation for the earlier success in reopening visual plasticity by diffuse treatment with chondroitinases in the adult rat (Pizzorusso et al., 2002). Resetting V1b to a juvenile state by function-blocking Otx2 antibody (Sugiyama et al., 2008) or the RK peptide here offer a more precise therapeutic tool.

Otx2 may thus serve as a "master regulator" of visual cortex plasticity during development and throughout adulthood. How might CP induction and closure be linked? Our initial report showed that Otx2 not only opens a CP but also leads to its premature closure (Sugiyama et al., 2008). This suggests that a threshold level of Otx2 initiates plasticity, which is eventually exceeded to limit plasticity in adulthood. A similar two-threshold model is proposed to explain the direct effects of GABA maturation on CP time course (Feldman, 2000; Spolidoro et al., 2009). PV cell development establishes the crucial excitatory-inhibitory balance conducive to plasticity (Hensch, 2005), but then these cells acquire PNNs, which terminate further rewiring by sustained Otx2 internalization (Fig. 8C). Loss of Otx2 in adulthood then leads to transient loss of PNNs and a reactivation of plasticity until both Otx2 and PNN levels recover (Fig. 6).

Plasticity thus reflects a threshold amount of Otx2 within PV cells with therapeutic relevance for recovery from amblyopia (Fig. 8). It will be important to evaluate the Otx2 content of PV cells in other paradigms (e.g., environmental conditions, fluoxetine) reported to support adult visual plasticity (Morishita and Hensch, 2008; Spolidoro et al., 2009; Bavelier et al., 2010). As appropriate delivery methods are devised, RK-related agents may not only restore vision to human amblyopes, they may potentially rescue other defects of CP brain development. Therapeutic strategies adjusting intercellular transfer of Otx2 into PV circuits may, for instance, be adapted more generally to rescue neurodevelopmental disorders of similar cellular etiology, such as autism spectrum disorders, fear extinction, and schizophrenia (Lewis et al., 2005; Gogolla et al., 2009a,b).

\section{References}

Balmer TS, Carels VM, Frisch JL, Nick TA (2009) Modulation of perineuronal nets and parvalbumin with developmental song learning. J Neurosci 29:12878-12885.

Bavelier D, Levi DM, Li RW, Dan Y, Hensch TK (2010) Removing brakes on adult brain plasticity: from molecular to behavioral interventions. J Neurosci 30:14964-14971.

Berardi N, Pizzorusso T, Maffei L (2004) Extracellular matrix and visual cortical plasticity: freeing the synapse. Neuron 44:905-908.

Brunet I, Weinl C, Piper M, Trembleau A, Volovitch M, Harris W, Prochiantz A, Holt C (2005) The transcription factor Engrailed-2 guides retinal axons. Nature 438:94-98. 
Brunet I, Di Nardo AA, Sonnier L, Beurdeley M, Prochiantz A (2007) The topological role of homeoproteins in the developing central nervous system. Trends Neurosci 30:260-267.

Bülow HE, Hobert O (2006) The molecular diversity of glycosaminoglycans shapes animal development. Annu Rev Cell Dev Biol 22:375-407.

Cardin AD, Weintraub HJ (1989) Molecular modeling of proteinglycosaminoglycan interactions. Arteriosclerosis 9:21-32.

Carulli D, Pizzorusso T, Kwok JC, Putignano E, Poli A, Forostyak S, Andrews MR, Deepa SS, Glant TT, Fawcett JW (2010) Animals lacking link protein have attenuated perineuronal nets and persistent plasticity. Brain 133:2331-2347.

Celio MR, Blümcke I (1994) Perineuronal nets-a specialized form of extracellular matrix in the adult nervous system. Brain Res Brain Res Rev 19:128-145.

Cheng HJ, Flanagan JG (1994) Identification and cloning of ELF-1, a developmentally expressed ligand for the Mek4 and Sek receptor tyrosine kinases. Cell 79:157-168.

Cruikshank SJ, Lewis TJ, Connors BW (2007) Synaptic basis for intense thalamocortical activation of feedforward inhibitory cells in neocortex. Nat Neurosci 10:462-468.

Di Lullo E, Haton C, Le Poupon C, Volovitch M, Joliot A, Thomas JL, Prochiantz A (2011) Paracrine Pax6 activity regulates oligodendrocyte precursor cell migration in the chick embryonic neural tube. Development 138:4991-5001.

Erisir A, Dreusicke M (2005) Quantitative morphology and postsynaptic targets of thalamocortical axons in critical period and adult ferret visual cortex. J Comp Neurol 485:11-31.

Fagiolini M, Katagiri H, Miyamoto H, Mori H, Grant SG, Mishina M, Hensch TK (2003) Separable features of visual cortical plasticity revealed by $\mathrm{N}$-methyl-D-aspartate receptor 2A signaling. Proc Natl Acad Sci U S A 100:2854-2859.

Feldman DE (2000) Inhibition and plasticity. Nat Neurosci 3:303-304.

Gallet A, Staccini-Lavenant L, Thérond PP (2008) Cellular trafficking of the glypican Dally-like is required for full-strength Hedgehog signaling and wingless transcytosis. Dev Cell 14:712-725.

Gianfranceschi L, Siciliano R, Walls J, Morales B, Kirkwood A, Huang ZJ, Tonegawa S, Maffei L (2003) Visual cortex is rescued from the effects of dark rearing by overexpression of BDNF. Proc Natl Acad Sci U S A 100:12486-12491.

Gogolla N, Leblanc JJ, Quast KB, Südhof TC, Fagiolini M, Hensch TK (2009a) Common circuit defect of excitatory-inhibitory balance in mouse model of autism. J Neurodev Disord 1:172-181.

Gogolla N, Caroni P, Lüthi A, Herry C (2009b) Perineuronal nets protect fear memories from erasure. Science 325:1258-1261.

Gordon JA, Stryker MP (1996) Experience-dependent plasticity of binocular responses in the primary visual cortex of the mouse. J Neurosci 16:3274-3286.

Gordon JA, Cioffi D, Silva AJ, Stryker MP (1996) Deficient plasticity in the primary visual cortex of alpha-calcium/calmodulin-dependent protein kinase II mutant mice. Neuron 17:491-499.

Härtig W, Derouiche A, Welt K, Brauer K, Grosche J, Mäder M, Reichenbach A, Brückner G (1999) Cortical neurons immunoreactive for the potassium channel Kv3.1b subunit are predominantly surrounded by perineuronal nets presumed as a buffering system for cations. Brain Res 842:15-29.

Hensch TK (2005) Critical period plasticity in local cortical circuits. Nat Rev Neurosci 6:877-888.

Hensch TK (2004) Critical period regulation. Annu Rev Neurosci 27:549-579.

Hensch TK, Gordon JA, Brandon EP, McKnight GS, Idzerda RL, Stryker MP (1998) Comparison of plasticity in vivo and in vitro in the developing visual cortex of normal and protein kinase $\mathrm{A} \mathrm{RI} \beta^{-}$mice. J Neurosci 18:2108-2117.

Holmes JM, Clarke MP (2006) Amblyopia. Lancet 367:1343-1351.
Iwai Y, Fagiolini M, Obata K, Hensch TK (2003) Rapid critical period induction by tonic inhibition in visual cortex. J Neurosci 23:6695-6702.

Jastrebova N, Vanwildemeersch M, Rapraeger AC, Giménez-Gallego G, Lindahl U, Spillmann D (2006) Heparan sulfate-related oligosaccharides in ternary complex formation with fibroblast growth factors 1 and 2 and their receptors. J Biol Chem 281:26884-26892.

Joliot A, Prochiantz A (2004) Transduction peptides: from technology to physiology. Nat Cell Biol 6:189-196.

Joliot AH, Triller A, Volovitch M, Pernelle C, Prochiantz A (1991b) alpha2,8-Polysialic acid is the neuronal surface receptor of antennapedia homeobox peptide. New Biol 3:1121-1134.

Joliot A, Pernelle C, Deagostini-Bazin H, Prochiantz A (1991a) Antennapedia homeobox peptide regulates neural morphogenesis. Proc Natl Acad Sci U S A 88:1864-1868.

Lehmann K, Löwel S (2008) Age-dependent ocular dominance plasticity in adult mice. PLoS One 3:e3120.

Lewis DA, Hashimoto T, Volk DW (2005) Cortical inhibitory neurons and schizophrenia. Nat Rev Neurosci 6:312-324.

Mataga N, Mizuguchi Y, Hensch TK (2004) Experience-dependent pruning of dendritic spines in visual cortex by tissue plasminogen activator. Neuron 44:1031-1041.

Miyata S, Komatsu Y, Yoshimura Y, Taya C, Kitagawa H. (2012) Persistent cortical plasticity by upregulation of chondroitin 6-sulfation. Nat Neurosci 2012;15:414-422, S1-S2.

Morishita H, Hensch TK (2008) Critical period revisited: impact on vision. Curr Opin Neurobiol 18:101-107.

Morishita H, Miwa JM, Heintz N, Hensch TK (2010) Lynx1, a cholinergic brake, limits plasticity in adult visual cortex. Science 330:1238-1240.

Mower GD (1991) The effect of dark rearing on the time course of the critical period in cat visual cortex. Brain Res Dev Brain Res 58:151-158.

Nowicka D, Soulsby S, Skangiel-Kramska J, Glazewski S (2009) Parvalbumincontaining neurons, perineuronal nets and experience-dependent plasticity in murine barrel cortex. Eur J Neurosci 30:2053-2063.

Pizzorusso T, Medini P, Berardi N, Chierzi S, Fawcett JW, Maffei L (2002) Reactivation of ocular dominance plasticity in the adult visual cortex. Science 298:1248-1251.

Pizzorusso T, Medini P, Landi S, Baldini S, Berardi N, Maffei L (2006) Structural and functional recovery from early monocular deprivation in adult rats. Proc Natl Acad Sci U S A 103:8517-8522.

Spolidoro M, Sale A, Berardi N, Maffei L (2009) Plasticity in the adult brain: lessons from the visual system. Exp Brain Res 192:335-341.

Stettler O, Joshi RL, Wizenmann A, Reingruber J, Holcman D, Bouillot C, Castagner F, Prochiantz A, Moya KL (2012) Engrailed homeoprotein recruits the adenosine A1 receptor to potentiate ephrin A5 function in retinal growth cones. Development 139:215-224.

Sugiyama S, Di Nardo AA, Aizawa S, Matsuo I, Volovitch M, Prochiantz A, Hensch TK (2008) Experience-dependent transfer of Otx2 homeoprotein into the visual cortex activates postnatal plasticity. Cell 134:508-520.

Wiesel TN, Hubel DH (1963) Effects of visual deprivation on morphology and physiology of cells in the cats lateral geniculate body. J Neurophysiol 26:978-993.

Wizenmann A, Brunet I, Lam JS, Sonnier L, Beurdeley M, Zarbalis K, Weisenhorn-Vogt D, Weinl C, Dwivedy A, Joliot A, Wurst W, Holt C, Prochiantz A (2009) Extracellular Engrailed participates in the topographic guidance of retinal axons in vivo. Neuron 64:355-366.

Yazaki-Sugiyama Y, Kang S, Câteau H, Fukai T, Hensch TK (2009) Bidirectional plasticity in fast-spiking GABA circuits by visual experience. Nature 462:218-221.

Ziegler A (2008) Thermodynamic studies and binding mechanisms of cellpenetrating peptides with lipids and glycosaminoglycans. Adv Drug Deliv Rev 60:580-597.

Ziegler A, Seelig J (2008) Binding and clustering of glycosaminoglycans: a common property of mono- and multivalent cell-penetrating compounds. Biophys J 94:2142-2149. 